\title{
Robustness and stabilization properties of monetary policy rules in Brazil
}

\author{
Ajax R. B. Moreira \\ Institute of Applied Economic Research (IPEA) \\ Marco A.F.H. Cavalcanti \\ Institute of Applied Economic Research (IPEA)
}

May 2001

KEYWORDS: Monetary policy rules, optimal monetary policy, parameter uncertainty, model uncertainty, Taylor rule.

JEL Classification: E52

Correspondence:

Ajax Moreira: Instituto de Pesquisa Econômica Aplicada, Av. Pres. Antonio Carlos 51/1508, Rio de Janeiro - RJ, CEP 20020-010, Brasil. Tel.: 55-21-38048145, e-mail: ajax@ipea.gov.br.

Marco Cavalcanti: Instituto de Pesquisa Econômica Aplicada, Av. Pres. Antonio Carlos 51/1716, Rio de Janeiro-RJ, CEP 20020-010, Brasil. Tel.: 55-21-38048120, e-mail: cavalcanti@ipea.gov.br. 


\begin{abstract}
Based on three versions of a small macroeconomic model for Brazil, this paper presents empirical evidence on the effects of parameter uncertainty on monetary policy rules and on the robustness of optimal and simple rules over different model specifications. By comparing the optimal policy rule under parameter uncertainty with the rule calculated under purely additive uncertainty, we find that parameter uncertainty should make policymakers react less aggressively to the economy's state variables, as suggested by Brainard's "conservatism principle", although this effect seems to be relatively small. We then informally investigate each rule's robustness by analyzing the performance of policy rules derived from each model under each one of the alternative models. We find that optimal rules derived from each model perform very poorly under altemative models, whereas a simple Taylor rule is relatively robust. We also find that even within a specific model, the Taylor rule may perform better than the optimal rule under particularly unfavorable realizations from the policymaker's loss distribution function.
\end{abstract}




\section{Introduction}

Currently, there seems to be a widespread belief among both academic researchers and policymakers that the conduct of monetary policy should be based on some kind of "rule". ${ }^{1}$ Unsurprisingly, the number of theoretical and empirical studies on monetary policy rules has been steadily increasing.

These studies have been concerned with two types of policy rules: optimal rules and simple rules. An optimal rule is the solution to a stochastic control problem in which policymakers aim to achieve some economic policy objective by managing their control instrument under the restrictions given by the macroeconomic model. The rule specifies the policymakers' setting of the instrument in response to all available information on the state of the economy as given by expected, current and lagged values of the system's variables. A simple rule, on the other hand, is a reaction function in which policymakers do not use all available information when setting values for the policy instrument. It may be obtained as the solution to an optimization problem as before, subject to the additional restriction that policy should respond to only a limited subset of variables in the system. In this case, the rule is defined as an efficient or optimized simple rule. But simple rules may also be derived in a completely ad hoc manner, by exogenously specifying values for the reaction function coefficients, as in the well-known original "Taylor rule" (Taylor (1993)).

The analysis of monetary policy rules raises a number of interesting issues. One set of questions we will be focusing on refers to the effects of various forms of uncertainty on policy rules. According to the certainty equivalence principle, due originally to Simon (1956) and Theil (1957), the solution to an optimal control problem in a stochastic framework will be identical to the one that would be obtained in a deterministic model as long as the following conditions are met: (a) the loss function is quadratic; (b) the model is linear; (c) the model structure is known; (d) there are no measurement errors. In other words, if the only source of uncertainty comes from the model equations' innovations (i.e. purely additive uncertainty), the optimal reaction function will not be affected by such uncertainty. In practice, however, the model structure is unknown and economic variables are imperfectly observed. This means that policymakers must rely on econometric estimates of parameters in possibly misspecified models and on indicators of relevant economic variables.

The main implication of these additional sources of uncertainty relates to the validity of the certainty equivalence principle. In the case of uncertainty on the true parameter values in a given model (i.e. multiplicative uncertainty, as it affects the system's multipliers), the optimal control problem still admits a closed-form solution, as shown by Chow (1975), but the optimal reaction function is no longer independent of the degree of uncertainty about the estimated parameters. In other words, certainty equivalence no longer holds. In this context, the best-known result is due to Brainard (1967), who showed how parameter uncertainty may proportionately reduce the policy

\footnotetext{
1 The distinction between rule-based and discretionary policies is not always clear. Following Woodford (1999) and McCallum (2000), we interpret a policy rule as a response to current economic conditions determined either by a pre-specified formula or by an optimisation routine designed in a "timeless perspective", i.e. ignoring each moment's specific conditions. According to this definition, we may classify as rules policies such as inflation targeting and others labelled by some authors as "discretionary" [Blinder (1998); Bernanke et alii (1999)].
} 
reaction function coefficients, thus making policymakers more cautious in the conduct of monetary policy. The idea that more uncertainty regarding the effects of monetary policy instruments should make policymakers more "conservative" is very intuitive and appears to be consistent with observed practices, which explains much of its popularity (Blinder (1998)). However, Brainard's "conservatism principle" may be of little empirical significance and may even be reversed under specific patterns of correlation among parameters. Some studies argue that monetary policy should indeed exhibit significantly less aggressive responses under parameter uncertainty, as shown by Sack (1998) and Martin and Salmon (1998) for optimal rules and by Hall et al. (1999) for efficient simple rules, but others show that this effect may be relatively modest (Peersman and Smets (1999), Estrella and Mishkin (1998), Rudebusch (1998)) or even have the opposite sign, i.e. more aggressive policy under parameter uncertainty (Shuetrim and Thompson (1999)). The effects of parameter uncertainty on monetary policy rules are therefore an empirical issue, and one of our objectives will be to investigate such effects in the context of a macroeconometric model for Brazil.

In the case of uncertainty related to the measurement of the economy's state variables, certainty equivalence depends on the specific way in which uncertainty enters the model. If it arises from the noisy observation of the relevant state variables, the optimal rule will still be certainty-equivalent, as shown by Chow (1970) in a linearquadratic backward-looking framework and by Svensson e Woodford (2000) in a model with rational expectations. But if it refers to a signal-extraction problem, in which the relevant state variables are not observed and policymakers are restricted to act on observable indicators of these variables, then certainty equivalence no longer holds and optimal responses should be "attenuated" as proposed by Brainard (Swanson (2000)). As regards efficient simple rules, the effects of this type of uncertainty are theoretically ambiguous but the empirical evidence also supports the conservatism principle (Smets (1998), Orphanides (1998), Peersman and Smets (1999), Drew and Hunt (2000)). In this paper we will not explicitly analyze this type of uncertainty, but by applying two different measures of the output gap to our macroeconomic model we may be able to indirectly investigate some of the consequences of using a mismeasured state variable.

Of course, uncertainty on the correct model structure is not restricted to parameter uncertainty. A much deeper form of uncertainty refers to the model's correct specification - which equations should be included in the model, which variables should enter each equation, etc. This is clearly the worst form of uncertainty for policymaking, as the optimal rule derived from a specific model may perform very poorly if that model differs significantly from the "true" model. It is also a much harder problem to analyze, as specification possibilities are virtually infinite. Some authors have tackled this issue by applying robust control techniques to the problem of finding policy rules that are reasonably robust to model misspecification (Sargent (1999), Tetlow and von zur Muehlen (1999)). However, we do not pursue this approach here. Instead, we follow Levin et al. $(1998,1999)$ who restrict their analysis to a few macroeconomic models and then investigate the performance of policy rules derived from each model under each one of the alternative models. This approach provides an informal check on the robustness of the various rules considered by identifying those rules that perform relatively well over a range of different models. Although the results are obviously dependent on the arbitrary selection of models to be analyzed, they may provide useful indication as to which rules are most likely to perform badly in the case of model misspecification. The evidence in Levin et al. $(1998,1999)$ suggests that simple policy rules are generally more robust than more complicated rules, which is a very intuitive 
result: as we adjust a rule to the specific dynamics of a given model, we increase the likelihood of making it inadequate for other models.

This brings us to the second main theme we will be concerned with: should policymakers adopt fully optimal monetary policy rules or simple rules in practice? The answer is closely related to how confident we are that the macroeconomic model at hand provides a reasonable approximation to economic reality. It is clear that within a specific model a simple rule could never outperform the optimal rule in terms of expected welfare loss; therefore, if we consider the model to be "good", we should in principle opt for the optimal rule. In practice, however, the adoption of the optimal rule does not guarantee the best performance. As discussed above, there may be considerable uncertainty regarding the correct model specification, which means that the choice between optimal and simple rules should take into account not only each rule's performance in a given model but also their robustness across other possible model specifications. Besides, even within a specific model it is possible for the optimal rule to deliver larger losses than a simple rule, if we happen to be in a particularly unfavorable situation drawn from the model's probability distribution. After all, the optimal rule only ensures that expected losses will be minimized. In order to shed some light on this issue we will investigate the following questions: How much do we gain within a specific model by adopting the optimal rule instead of a simple one? Does the optimal rule perform well 'under risk', i.e. in unfavorable conditions? How robust are simple and optimal rules over a range of possible model specification?

Some evidence on these issues suggests that the performance of efficient simple rules is very similar to the performance of more complex optimal rules (Rudebusch $\mathrm{e}$ Svensson (1998), Peersman e Smets (1998), Drew and Hunt (2000)). This is an interesting result but it may simply be due to specific model structures that generate simple rules that are "similar" to the fully optimal rules. If, for example, the coefficients on contemporaneous output gap and inflation in the optimal rule account for a large part of the policy reaction we should expect an optimized Taylor rule to be "similar" to the optimal rule and therefore to have similar stabilization properties. We therefore find that a more interesting exercise is to compare the performance of optimal rules and ad hoc simple rules such as the original Taylor rule.

The paper's contribution is twofold. First, it provides additional empirical evidence on the relation between uncertainty and policy rules, which may improve our understanding of the extent to which Brainard's conservatism principle may be expected to hold in practice. Second, it compares the relative performance of optimal rules and a simple Taylor rule over three different model specifications, thus allowing an informal analysis of each rule's robustness and contributing to the literature on the choice between optimal and simple rules.

The paper is organized as follows. In Section 2 we present and estimate three macroeconometric models for Brazil. In Section 3 we calculate the optimal policy rules for each model and analyze their robustness and stabilization properties. We also compare these rules' performance with a simple Taylor rule. In Section 4 we summarize our results and make our final comments. 


\section{Alternative model specifications for Brazil}

According to McCallum (1999), the standard framework for monetary analysis in the recent literature has relied on macroeconomic models with three basic components: (i) an IS-type relation (or set of relations) that specifies the effects of monetary policy on aggregate demand and output; (ii) a price adjustment equation (or set of equations) that specifies the effects of the output gap and price expectations on inflation; and (iii) a monetary policy rule that specifies the policymakers' setting of a short-term instrument (usually the interest rate) in response to the state of the economy as given by expected, current and lagged values of the system's variables.

We follow this standard framework and set up three alternative model specifications, labeled models 1 to 3 . We assume from the outset that all three models are equally likely descriptions of the world. Our basic model is centered on the following set of equations:

$u_{t}=\alpha_{1}^{u}+\alpha_{2}^{u} u_{t-1}+\alpha_{3}^{u} u_{t-2}+\alpha_{4}^{u}\left(r_{t-1}-E_{t-1} \pi_{t}\right)+\varepsilon_{t}^{u}$

$\pi_{t}=\alpha_{1}^{\pi}+\alpha_{2}^{\pi} \pi_{t-1}+\alpha_{3}^{\pi} u_{t-4}+\alpha_{4}^{\pi} d_{t-1}+\varepsilon_{t}^{\pi}$

where $u_{t}$ is the output gap; $r_{t}$ is the nominal interest rate; $\pi_{t}$ is monthly inflation in the consumer price index; $E_{t-1} \pi_{t}$ are inflation expectations based on information available at time $t ; d_{t}$ is monthly nominal exchange rate depreciation. ${ }^{2}$ Equation (1) is a reduced form IS relation whereby real interest rates affect aggregate demand and thus the output gap. Equation (2) is a price adjustment equation in which current inflation depends on previous inflation, on exchange rate depreciation and on the output gap. The lag structure was chosen in the estimation process, as described below.

We assume for simplicity that inflation expectations are backward looking and given by the observed average rate in the previous quarter, i.e.

$E_{t-1} \pi_{t}=\left(\pi_{t-1}+\pi_{t-2}+\pi_{t-3}\right) / 3$

The nominal exchange rate is determined by an uncovered interest parity condition; assuming that changes in exchange rate expectations, foreign interest rates and the risk premium all follow random walks, we may express exchange rate depreciation as: ${ }^{3}$

$d_{t}=-\Delta r_{t}+\varepsilon_{t}^{d}$

where $\varepsilon_{t}^{d}$ captures innovations to the risk premium, foreign interest rates and expectations.

Equations (1) to (4) complete Model 1. The output gap variable used in the model is measured as: ${ }^{4}$

\footnotetext{
${ }^{2}$ See the Appendix 1 for a detailed description of the data.

${ }^{3}$ See for example Bogdanski et al. (1999).
} 
$u_{t}=y_{t}-y_{i}^{*}$

where $y$ and $y^{*}$ are seasonally adjusted actual and potential GDP, respectively. We assume a deterministic trend for potential GDP, which is given by

$y_{i}^{*}=y_{t-1}^{*}+\delta$

From the actual GDP series and equations (5) and (6) we may calculate the output gap and use it in equations (1) and (2) above to estimate and solve Model 1.

Next we consider two alternative specifications. In Model 2 we keep the basic structure given by equations (1)-(4) intact and simply change the potential GDP definition (and consequently the output gap $u_{t}$ ). We now assume that potential GDP has a stochastic trend and is given by:

$y_{t}^{*}=\phi y_{t-1}^{*}+(1-\phi) y_{t-1}+\delta$

so that the output gap is calculated from (5), (7) and the actual GDP series.

Comparison of results from models 1 and 2 may therefore help us infer the implications of alternative definitions of potential GDP and the output gap. Equations (6) and (7) may be interpreted as polar cases in the class of potential GDP models that is so popular in the literature on monetary policy rules.

In Model 3, on the other hand, we keep the hypothesis of a deterministic potential product and change the specification of aggregate demand. We replace equation (1) with a more disaggregated specification that includes equations for the first differences of consumption $\left(\mathrm{c}_{\mathrm{t}}\right)$, investment $\left(\mathrm{i}_{\mathrm{t}}\right)$ and net exports of goods and non-factor services $\left(x_{t}\right):^{5}$

$\Delta c_{t}=\alpha_{1}^{c}+\alpha_{2}^{c} \Delta c_{t-1}+\alpha_{3}^{c}\left(r_{t-1}-E_{t-1} \pi_{t}\right)+\alpha_{4}^{c} D_{1}+\alpha_{5}^{c} D_{2}+\varepsilon_{t}^{c}$

$\left.\Delta_{t}={ }_{1}^{i}+\alpha_{2} \Delta_{t-1}+\alpha_{3}^{i} \Delta_{2}+{ }_{4}^{i}{ }_{t-1}-{ }_{-1} \pi_{t}\right)+\alpha_{4}^{i}+{ }^{i}$

$\left.\Delta_{t}=\alpha_{1}^{x} \Delta_{-1}+{ }_{2}^{x} t_{1}-\pi_{-1}\right)+\alpha_{3}^{x}{ }_{1}{\underset{4}{2}}_{2}^{x}+\alpha_{5}+\alpha_{6}^{x}{ }_{4}+$

GDP is given by

$y_{t}=c+, x_{t}$

\footnotetext{
${ }^{4}$ Note that variables are not in logarithms, so that $(5)$ is an unusual definition for the output gap.

behavior of potential GDP. The reason for adopting this particular specification is that it makes our life much easier when comparing results from Model 3. We should point out that our estimation results are

${ }^{5}$ D1, D2, D3 and D4 denote dummy variables for 1996.1, 1999.3, 1999.1 and 1999.11, respectively. The

monthly consumption and exports series (see Appendix 1). The other dummies refer to periods of exchange rate instability following the transition to a floating exchange rate system in 1999.
} 
and we may find an expression for the output gap by using (5) together with (11) and (6):

$u_{t}=u_{t-1}+\Delta c_{t}+\Delta i_{t}+\Delta x_{t}-\delta$

Equations (8), (9), (10) and (12) therefore replace equation (1) as determinants of the output gap. The other equations in the model are basically unchanged, with the exception of equation (2), to which we now add two dummy variables D5 and D6: ${ }^{6}$

$\pi_{t}=\alpha_{1}^{\pi}+\alpha_{2}^{\pi} \pi_{t-1}+\alpha_{3}^{\pi} u_{t-4}+\alpha_{4}^{\pi} d_{t-1}+\alpha_{5}^{\pi} D_{5}+\alpha_{6}^{\pi} D_{6}+\varepsilon_{t}^{\pi}$

Model 3 thus includes equations (2'), (3), (4), (8), (9), (10) and (12). By comparing the results from this model with results from Model 1 we may infer the effects on policy rules of alternative specifications of aggregate demand.

We should note that, unlike models 1 and 2, Model 3 is able to capture a direct effect of real exchange rate devaluation (proxied by $d_{t-1}-\pi_{t-1}$ ) on aggregate demand.

\subsection{Estimation results}

Models 1 and 2 are estimated using monthly data from 1995.1 to 2000.12 , while model 3 uses data from 1995.11 to 2000.12 . The use of such short datasets is warranted by Brazil's macroeconomic environment, which was very unstable up to mid-1994, with exceptionally high inflation rates and frequent regime changes, and relatively stable afterwards, as a result of the 1994 Real Plan. This is a clear structural break and we therefore believe that the estimation of economic relations involving nominal variables should only begin in 1995 , i.e. when inflation rates finally declined to reasonably low levels. Of course, the limited amount of degrees of freedom in the estimation should make us particularly cautious in interpreting our results. Model 3 uses an even smaller sample due to the fact that some of the relevant series are available only from 1995.8.

The lag structure and variables in each equation were selected according to the following criteria: (i) key coefficients should have the expected signs and be significant at least at $10 \%$ significance level; (ii) there should be no residual autocorrelation; (iii) we should not reject parameter constancy; (iv) models satisfying the first three criteria should be ranked according to information criteria. After conducting a specification search based on these criteria, we arrived at the final specification reported above. ${ }^{7}$

The estimated coefficients are shown in Table 1 . We estimated by SURE equations (1) and (2) for models 1 and 2, and equations (2'), (8), (9) and (10) for Model 3.

\footnotetext{
${ }^{6}$ D5 is a dummy variable with value 1 in 1996.3, 1996.8, 1997.2, 1997.8 and 1998.8 and zero otherwise; it refers to periods of unusually large reductions in the inflation rate within the fixed exchange rate regime subsample 1995.11-1998.12. D6 is a dummy variable with value 1 in 1999.7, 1999.10 and 2000.7 and zero otherwise; it refers to periods of unusually large increases in the inflation rate within the floating exchange rate regime subsample 1999.1-2000.12.

${ }^{7}$ We used a Lagrange-multiplier test to test for residual autocorrelation and Chow 1-step ahead and break-point tests to test for parameter constancy.
} 
Table 1 - Estimation results

\begin{tabular}{cccccccc}
\hline Model & Equation & \multicolumn{7}{c}{ Coefficients } \\
\cline { 2 - 7 } & \multicolumn{1}{c}{1} & 2 & 3 & 4 & 5 & 6 \\
\hline M1 & 1 & $0.686(1.3)$ & $0.415(3.9)$ & $0.397(3.8)$ & $-0.548(1.6)$ & - & - \\
& 2 & $0.167(2.2)$ & $0.682(8.5)$ & $0.032(2.0)$ & $0.018(1.7)$ & - & - \\
\hline M2 & 1 & $0.954(1.9)$ & $0.265(2.5)$ & $0.261(2.6)$ & $-0.945(2.9)$ & - & - \\
& 2 & $0.213(2.8)$ & $0.679(8.7)$ & $0.048(2.4)$ & $0.019(1.8)$ & - & - \\
\hline M3 & 2 & $0.141(2.3)$ & $0.690(9.2)$ & $0.022(1.5)$ & $0.014(2.0)$ & $0.475(3.5)$ & $1.096(6.6)$ \\
& 8 & $0.703(1.9)$ & $-0.154(1.9)$ & $-0.390(1.6)$ & $8.646(7.1)$ & $2.838(2.4)$ & - \\
& 9 & $0.867(3.5)$ & $-0.821(7.8)$ & $-0.474(4.5)$ & $-0.526(3.2)$ & - & - \\
& 10 & $-0.280(3.1)$ & $0.060(1.5)$ & $-8.030(6.3)$ & $-1.500(0.9)$ & $1.630(1.4)$ & $-2.700(2.2)$ \\
\hline
\end{tabular}

Estimation period - M1/M2: 1995.1-2000.12; M3: 1995.11-2000.12

Estimation method - SURE ( $t$-statistics in parentheses)

Coefficients in the potential GDP equations were selected so as to maximize 6step-ahead predictive power. Using the sample period from 1991.1 to 2000.12 we estimated the following coefficients: $\delta=0.3, \phi=0.92$.

Estimation results are not particularly good, as we note some rather low t-statistics and the need for several dummy variables in Model 3. However, our basic selection criteria are satisfied: all key coefficients have the expected signs and we do not reject either the absence of residual autocorrelation or parameter constancy. ${ }^{8}$ Appendix 2 presents graphs with Chow tests for each model.

It is interesting to compare the estimated coefficients for the real interest rate in equation (1) and for the output gap in equation (2) under models 1 and 2. As expected, both coefficients are smaller in Model 1 , in which the output gap is derived from a deterministic potential product. For obvious reasons, these results will have important implications for the calculation of the optimal policy rule in the next section.

\section{Calculation of the optimal monetary policy rule}

The literature usually characterizes monetary policy as the management of a short-term instrument, such as the monetary base or interest rates, with the objective of minimizing expected deviations of inflation and the output gap from prespecified target levels (see, inter alia, Svensson (1996, 1997), Blinder (1998), Walsh (1998)). A typical problem for the policymakers would therefore be to

$$
\begin{aligned}
& \min _{z} G=E_{0}\left\{\sum_{t=0}\left(y_{t}-y_{t}\right)^{2}\right. \\
& \text { subject to } y_{t}=A y_{t-1}+B z_{t-1}+a_{t}+e_{t} \\
& e_{t} \sim(0, S)
\end{aligned}
$$

where $y$ are target variables with target level $y^{*}, z$ is a vector of control variables, $a$ is a vector of aggregate effects from exogenous variables, $e$ is a vector of stochastic shocks and $A$ and $B$ are non-stochastic parameter matrices. ${ }^{9}$ It is possible to show that the solution to this linear-quadratic problem is a linear deterministic function of the target variables (Chow, 1975):

\footnotetext{
${ }^{8}$ According to the 1-step Chow tests we might reject parameter stability for a couple of periods, but we believe this may be due to the presence of outliers.

${ }^{9}$ Note that this is a quite general problem, as difference equations of any order may be reparameterized as first-order difference equations by including additional endogenous variables.
} 


$$
\mathrm{z}_{\mathrm{t}}=\mathrm{Fy}_{\mathrm{t}}+\mathrm{f}_{\mathrm{t}}
$$

This is a remarkable result known as the certainty equivalence principle: the solution to an optimal control problem in a stochastic framework may be obtained analytically and is identical to the one that would be obtained in a similar model without the stochastic term. Function (15) is called the optimal reaction function (RF). ${ }^{10}$

It is clear that given the model parameters $C=(A, B)$ we may calculate the parameters in the reaction function, $F \mid C$. However, model parameters are usually estimated, so that we may only know their probability distribution $\mathrm{C} \sim \mathrm{N}(\hat{C}, \mathrm{~W})$. In this case, the policymakers problem is to

$$
\begin{aligned}
& \min _{\mathrm{z}} \mathrm{P}=\mathrm{E}_{0}\left\{\sum _ { \mathrm { t } = 0 } \left(\mathrm{y}_{\left.\mathrm{t}-\mathrm{y}_{\mathrm{t}}\right)^{2}}\right.\right. \\
& \text { subject to } \mathrm{y}_{\mathrm{t}}=\mathrm{Ay}_{\mathrm{t}-1}+\mathrm{Bz}_{\mathrm{t}-1}+\mathrm{a}_{\mathrm{t}}+\mathrm{e}_{\mathrm{t}} \quad \mathrm{e}_{\mathrm{t}} \sim(0, \mathrm{~S}),(\mathrm{A}, \mathrm{B})=\mathrm{C} \sim \mathrm{N}(\hat{C}, \mathrm{~W})
\end{aligned}
$$

In this new problem the presence of multiplicative uncertainty implies that certainty equivalence no longer holds, but we may still calculate a linear optimal reaction function, as shown by Chow (1975).

Following Chow (1975), we now show how to calculate the optimal reaction function for problems (14) and (16) in turn. Let $\rho$ be a discount factor and R be a weight matrix that determines the relative importance of each endogenous variable's squared deviations from target. $R$ is isually taken to be diagonal. The loss function may be decomposed in a deterministic part $(\mathrm{K})$ and a stochastic part $(\mathrm{V})$ defined below:

$$
\begin{aligned}
& \mathrm{K}=\sum \rho^{\mathrm{t}}\left\{\left(\mathrm{E}\left(\mathrm{y}_{\mathrm{t}}\right)-\mathrm{y}^{*}\right)^{\prime} \mathrm{R}\left(\mathrm{E}\left(\mathrm{y}_{\mathrm{t}}\right)-\mathrm{y}^{*}\right)\right. \\
& \left.\mathrm{V}=\left(\mathrm{y}_{\mathrm{t}}-\mathrm{E}\left(\mathrm{y}_{\mathrm{t}}\right)\right)^{\prime} \mathrm{R}\left(\mathrm{y}_{\mathrm{t}}-\mathrm{E}\left(\mathrm{y}_{\mathrm{t}}\right)\right)\right\} \\
& \mathrm{P}(\mathrm{z})=\mathrm{E}_{0}\left\{\sum \rho^{\mathrm{t}}\left(\mathrm{y}_{\mathrm{t}}-\mathrm{y}^{*}\right)^{\prime} \mathrm{R}\left(\mathrm{y}_{\mathrm{t}}-\mathrm{y}^{*}\right)\right\}=\mathrm{K}(\mathrm{z})+\mathrm{E}_{0} \mathrm{~V}(\mathrm{z})
\end{aligned}
$$

The optimal reaction function for problem (14) with known parameters is given by the terminal condition for the value function $\left(\mathrm{P}_{\mathrm{T}}=\mathrm{R}, \mathrm{h}_{\mathrm{T}}=\mathrm{Ry} \mathrm{H}^{*}\right)$ and by the Riccati equations. These equations are solved iteratively from the last to the first period and give us each period's value function $\left(\mathrm{P}_{t}, \mathrm{~h}_{\mathrm{t}}\right)$, which is used in the calculation of the reaction function. As the econometric model may include time-dependent exogenous variables $\left(\mathrm{a}_{\mathrm{t}}\right)$, we use the indicated non-stationary solution. Nonetheless, the reported optimal reaction function refers to the initial period.

$$
\begin{aligned}
& P_{t-1}=R+\rho A^{\prime} R A-\rho A^{\prime} P_{t} B\left(B^{\prime} P_{t} B\right)^{-1} B^{\prime} P_{t} A \\
& h_{t-1}=R y^{*}-\left(A+B F_{t}\right)^{\prime}\left(P_{t} a_{t}-h_{t}\right) \\
& z_{t}=-\left(B^{\prime} P_{t} B\right)^{-1} B^{\prime} P_{t} A y_{t}\left(B^{\prime} P_{t} B\right)^{-1} B^{\prime}\left(P_{t} a_{t}-h_{t}\right)=F_{t} y_{t}+f_{t}
\end{aligned}
$$

\footnotetext{
${ }^{10}$ The linear-quadratic framework is crucial for the derivation of certainty-equivalence. It is sometimes criticized as being "unrealistic" and "arbitrary" but, as pointed out by Blinder (1998, p.10), for small changes in macroeconomic variables "any model of an economy is approximately linear and any convex objective function is approximately quadratic". Besides, some studies show that, under certain conditions, the hypothesis of a quadratic loss function is not necessary for the validity of the certainty-equivalence principle [Chadha e Schellekens (1999)].
} 
For problem (16) with unknown parameters we use the same terminal condition $\left(\mathrm{P}_{\mathrm{T}}=\mathrm{R}, \mathrm{h}_{\mathrm{T}}=\mathrm{Ry}^{*}\right)$ and the expected value of terms in brackets in the equations below are obtained by simulation. We generate 1000 realizations of model parameters $\mathrm{C} \sim \mathrm{N}(\hat{C}, \mathrm{~W})$ using the estimated distribution of each macroeconomic model in Section 2. Once again, we use the non-stationary solution and the optimal reaction function refers to the initial period.

$$
\begin{aligned}
& E_{t}\left\{P_{t-1}\right\}=R+\rho E_{t}\left\{A^{\prime} R A-\rho A^{\prime} P_{t} B\left(B^{\prime} P_{t} B\right)^{-1} B^{\prime} P_{t} A\right\} \\
& E_{t}\left\{h_{t-1}\right\}=R y^{*}-E_{t}\left\{(A+B F){ }^{\prime}\left(P_{t} a_{t}-h_{t}\right)\right\} \\
& z_{t}=-\left\{E_{t}\left(B^{\prime} P_{t} B\right)\right\}^{-1} E_{t}\left(B^{\prime} P_{t} A\right)-\left\{E_{t}\left(B^{\prime} P_{t} B\right)\right\}^{-1} E_{t}\left\{B^{\prime}\left(P_{t} a_{t}-h_{t}\right)\right\}=F_{t} y_{t}+f_{t}
\end{aligned}
$$

The above procedures allow us to calculate the optimal reaction function for each one of the models presented in Section 2. But we do not know which empirical model provides the best approximation to the "true" model and are therefore uncertain as to which policy rule should be regarded as the best overall rule.

One way to approach this question is to investigate each rule's robustness by calculating the policymaker's loss under each model $(\mathrm{m})$ given each reaction function (n), i.e. $P_{m} \mid F_{n}$. The policymaker's loss may be obtained by simulating 1000 realizations of model parameters $\mathrm{C} \sim \mathrm{N}(\hat{C}, \mathrm{~W})$ and disturbances $\mathrm{e}_{\tau} \sim(0, \mathrm{~S})$, which generate trajectories for $(y, z)$, and then using expressions (17)-(19) to calculate the expected loss.

In the following exercises we assume that policymakers target a $0.487 \%$ monthly inflation rate (corresponding to $6 \%$ per year) and a zero monthly output gap, with equal weights. Results would be obviously different if we adopted some other criterion, such as to target average inflation over one year.

In all cases we assume the discount factor to be 1 and present results for the deviation of $\mathrm{E}(\mathrm{y})$, given by $\mathrm{K}$, and the deviation of $\mathrm{y}$, given by $\mathrm{P}$.

\subsection{Results}

Table 2 presents the optimal reaction function coefficients for each model estimated in Section 2, both under the hypothesis of purely additive uncertainty, i.e. known parameters $[\mathrm{F} \mid \mathrm{E}(\mathrm{C})]$, and under the hypothesis of additive and multiplicative uncertainty, i.e. unknown parameters $[\mathrm{F} \mid \mathrm{C}]$. From this table we may draw some very interesting conclusions.

First, comparison between response coefficients in $\mathrm{F} \mid \mathrm{E}(\mathrm{C})$ and in $\mathrm{F} \mid \mathrm{C}$ within each model shows that the presence of multiplicative uncertainty should make policymakers react less aggressively to the economy's state variables, as suggested by Brainard's "conservatism principle". However, this effect seems to be relatively small in most cases, which is consistent with the findings in Peersman and Smets (1999), Estrella and Mishkin (1998) and Rudebusch (1999), inter alia.

Second, comparison among coefficients across models shows remarkable similarities in the optimal response to inflation but quite different responses to the output gap. For example, for each unit increase in the current output gap the interest rate should be raised about 0.57-0.76 according to Model 1 and about $0.25-0.28$ according to 
Model 2. In part, this may be explained by the different potential GDP definitions used in M1 and M2. In Model 1, the use of a deterministic potential output implies: (i) an output gap with larger variance; (ii) smaller effects of monetary policy on the output gap; (iii) smaller effects of the output gap on inflation (see Table 1). As a consequence, optimal policy must respond more aggressively to the output gap in order to keep both the output gap and inflation under control.

Third, it is interesting to analyze the coefficient on the lagged nominal interest rate, which enters the optimal reaction function through equation (4) and may be interpreted as a measure of interest-rate smoothing - the higher the coefficient, the more sluggish interest rate movements would tend to be. According to our findings, this coefficient is very small in all cases, especially in models 1 and 2 (when they are nearly zero); we therefore conclude that according to our empirical models optimal policy should incorporate very little interest rate smoothing.

Table 2 - Optimal reaction functions

\begin{tabular}{llcccccccccc}
\hline Model & $\mathrm{RF}$ & $\Delta \mathrm{c}$ & $\Delta \mathrm{i}$ & $\Delta \mathrm{i}_{-1}$ & $\Delta \mathrm{x}$ & $\pi$ & $\pi_{-1}$ & $\pi_{-2}$ & $\mathrm{u}$ & $\mathrm{u}_{-1}$ & $\mathrm{r}_{-1}$ \\
\hline M1 & $\mathrm{F} \mid \mathrm{E}(\mathrm{C})$ & - & - & - & - & 0.359 & 0.330 & 0.330 & 0.760 & 0.724 & 0.000 \\
& $\mathrm{~F} \mid \mathrm{C}$ & - & - & - & - & 0.352 & 0.330 & 0.329 & 0.568 & 0.540 & 0.000 \\
\hline M2 & $\mathrm{F} \mid \mathrm{E}(\mathrm{C})$ & - & - & - & - & 0.350 & 0.330 & 0.330 & 0.283 & 0.278 & 0.000 \\
& $\mathrm{~F} \mid \mathrm{C}$ & - & - & - & - & 0.346 & 0.330 & 0.329 & 0.250 & 0.243 & 0.000 \\
\hline M3 & $\mathrm{F} \mid \mathrm{E}(\mathrm{C})$ & 0.828 & 0.180 & -0.480 & 0.700 & 0.256 & 0.311 & 0.311 & 0.979 & 0.000 & 0.058 \\
& $\mathrm{~F} \mid \mathrm{C}$ & 0.750 & 0.160 & -0.439 & 0.637 & 0.262 & 0.313 & 0.313 & 0.887 & 0.000 & 0.053 \\
\hline
\end{tabular}

The following results refer to the application of the optimal rules derived under the hypothesis of both additive and multiplicative uncertainty, i.e. $[F \mid C]$.

Table 3 presents each model's largest characteristic roots before applying the optimal policy rule (the "free"case) and after applying it (the "controlled" case). We can see that the system is unstable in the absence of the policy rule but becomes stable when the latter is operative. As expected, the policy rule stabilizes the system.

Table 3 - Characteristic roots for models 1 to 3: modulus $(>0.5)$ and cycles

\begin{tabular}{lllll|}
\hline & Free & & & Controlled \\
\hline Model & 1 & 2 & 3 & 1 \\
\hline M1 & 0.93 & $0.57(16.8)$ & & 0.70 \\
M2 & 0.90 & 0.65 & $0.65(10.2)$ & 0.70 \\
M3 & 1 & $0.69(2.8)$ & 0.68 & 0.70 \\
\hline \multicolumn{4}{c}{ * Cycles in parentheses (in months) }
\end{tabular}

In Table 4 we report the welfare losses obtained under each model given the optimal reaction function from each model in turn. We normalize each loss by the corresponding model's optimal rule, so that the expected loss in M1 given M1's optimal rule (RF|M1) is 1; the expected loss in M1 given M2's optimal rule (RF|M2) is $36 \%$ higher; and so on. We also calculate losses given that monetary policy follows the classic simple Taylor rule (TR). 
Table 4 - Loss given $E(Y)$ in models 1 to 3 under each model's RF (normalized by the corresponding model's RF)

\begin{tabular}{|c|c|c|c|c|c|c|c|c|}
\hline & \multicolumn{4}{|c|}{ Mean } & \multicolumn{4}{|c|}{ Value under risk* } \\
\hline$V(u)+V(\pi)$ & TR & RF|M1 & RFIM2 & RF|M3 & TR & RFIM1 & RF|M2 & RF|M3 \\
\hline$\overline{\mathrm{M} 1}$ & 1.16 & 1.00 & 1.36 & & 3.35 & 9.42 & 4.40 & \\
\hline M2 & 1.04 & 2.65 & 1.00 & & 2.69 & 2159 & 2.41 & \\
\hline M3 & 1.27 & 7.09 & 2.33 & 1.00 & 3.39 & 113 & 6.88 & 5.11 \\
\hline
\end{tabular}

Given any specific model, we note that the adoption of the optimal rule calculated from some other model always leads to very poor results in terms of expected loss. The additional loss caused by using the "wrong" optimal policy ranges from $36 \%$ in the best case (use of RF|M2 in M1) to $600 \%$ in the worst case (use of $\mathrm{RF} \mid \mathrm{M} 1$ in $\mathrm{M} 3$ ).

On the other hand, the performance of the simple Taylor rule across models $1-3$ is quite robust. In every model, the Taylor rule is ranked second, losing only to the model's own optimal rule in terms of expected loss. In other words, given any specific model it is always better to adopt the Taylor rule than to adopt the "wrong" optimal rule calculated from some other model. Even more important, the performance of this simple rule is reasonably close to each model's own optimal rule; the additional loss from using the Taylor rule varies from only $4 \%$ in Model 2 to $27 \%$ in Model 3.

The Taylor rule's robustness is even more remarkable when we consider values "under risk", i.e. under particularly unfavourable realizations from the model's probability distribution. ${ }^{11}$ In such circumstances, the Taylor rule's performance deteriorates much less than the optimal rules. Under models 1 and 3, the Taylor rule performs even better than those models' own optimal rules. This is a very interesting result: even within a specific model, the adoption of the optimal rule does not guarantee the best performance in practice. The reason for this should be clear: the optimal rule is calculated so as to minimize expected losses, but the probability distribution for losses may be such that in practice other rules may provide better performance, as Table 4 shows.

Tables 5 to 7 give a more detailed account of the results from our exercise. In each table, we report the variances of the output gap, inflation and interest rates calculated in a specific model under each possible policy rule. We also report variances of consumption, investment and net exports for Model 3. Note that the first line in each of these tables is total welfare loss and is therefore the same as the corresponding line in Table 4.

${ }^{11}$ We take the $95^{\text {th }}$ percentile of the loss probability distribution function as a proxy for "value under risk". 
Table 5 - Variance of $E(Y)$ in M1 under M1's and M2's RF (normalized by M1's RF)

\begin{tabular}{|l|lrr|rrr|}
\hline & \multicolumn{3}{|l|}{ Mean } & \multicolumn{4}{|c|}{ Value under risk } \\
\hline & TR & RF|M1 & RF|M2 & TR & RF|M1 & RF|M2 \\
\hline$V(u)+V(\pi)$ & 1.16 & 1.00 & 1.36 & 3.35 & 9.42 & 4.40 \\
$V(u)$ & 1.18 & 1.00 & 1.38 & 3.56 & 10.35 & 4.70 \\
$V(\pi)$ & 0.90 & 1.00 & 1.02 & 3.15 & 4.08 & 3.96 \\
$V(r)$ & 0.87 & 1.00 & 0.81 & 1.47 & 2.31 & 1.38 \\
\hline
\end{tabular}

Table 6 - Variance of $E(Y)$ in M2 under M1's and M2's RF (normalized by M2's RF)

\begin{tabular}{l|lrrrrrr}
\hline & \multicolumn{3}{l}{ Mean } & \multicolumn{4}{l}{ Value under risk } \\
\hline & TR & RF|M1 & RF|M2 & TR & RF|M1 & RF|M2 \\
\hline$V(u)+V(\pi)$ & 1.04 & 2.65 & 1.00 & 2.69 & 2159.07 & 2.41 \\
$V(u)$ & 1.06 & 2.79 & 1.00 & 2.84 & 2356.90 & 2.52 \\
$V(\pi)$ & 0.92 & 1.33 & 1.00 & 2.67 & 55.86 & 2.98 \\
$V(r)$ & 1.18 & 1.70 & 1.00 & 1.75 & 461.81 & 1.49 \\
\hline
\end{tabular}

Table 7 - Variance of $\mathrm{E}(\mathrm{Y})$ in M3 under each model's RF (normalized by M3's RF)

\begin{tabular}{l|lrrrrrrrr}
\hline & \multicolumn{1}{|l}{ Mean } & \multicolumn{6}{c|}{ Value under risk } \\
\hline & TR & RF|M1 & RF|M2 & RF|M3 & TR & RF|M1 & RF|M2 & RF|M3 \\
\hline$V(u)+V(\pi)$ & 1.27 & 7.09 & 2.33 & 1.00 & 3.39 & 113.51 & 6.88 & 5.11 \\
$V(u)$ & 1.29 & 7.31 & 2.37 & 1.00 & 3.46 & 118.43 & 7.16 & 5.29 \\
$V(\pi)$ & 0.97 & 2.59 & 1.50 & 1.00 & 4.19 & 12.19 & 6.03 & 4.88 \\
$V(r)$ & 0.89 & 1.61 & 0.86 & 1.00 & 1.51 & 14.49 & 1.40 & 2.00 \\
$V(\Delta \mathrm{c})$ & 0.82 & 2.81 & 0.71 & 1.00 & 3.00 & 99.45 & 2.16 & 7.11 \\
$V(\Delta \mathrm{i})$ & 0.81 & 1.77 & 0.78 & 1.00 & 2.07 & 43.66 & 1.84 & 3.45 \\
$V(\Delta \mathrm{x})$ & 1.00 & 1.14 & 1.02 & 1.00 & 3.42 & 4.67 & 3.46 & 3.78 \\
\hline
\end{tabular}




\section{Conclusion}

Based on three versions of a small macroeconometric model for Brazil, this paper has provided empirical evidence on the relation between uncertainty and monetary policy rules and on the robustness of optimal and simple rules across different model specifications. Our main findings were as follows:

(1) The presence of multiplicative uncertainty should make policymakers react less aggressively to the economy's state variables, as suggested by Brainard's "conservatism principle", although this effect seems to be relatively small.

(2) Optimal policy should respond more aggressively to the output gap when potential output is deterministic than when it is stochastic.

(3) The simple Taylor rule is relatively robust across model specifications, whereas the optimal rules derived from each model perform very poorly under alternative models.

(4) Even within a specific model, the Taylor rule may perform better than the optimal rule under particularly unfavourable realizations from the policymaker's loss distribution function.

Needless to say, these conclusions are dependent on the specific model structures used, so that we should be careful in interpreting them. One particular feature of our models, which may seem inappropriate in the case of Brazil and therefore recommends extra caution in accepting the above conclusions, refers to the absence of links between monetary and fiscal policy. As changes in interest rates affect the public debt service, the existence of a large outstanding debt places an additional constraint on monetary policymaking, which probably should be taken into consideration by the authorities when setting the interest rate. As a useful extension to our results, it would be interesting to build a similar model that accounts for such effects. 


\section{References}

Andrade, J. and Divino, J.A. (2000) Optimal rules of monetary policy for Brazil, Mimeo.

Ball, L. (1999) Efficient rules for monetary policy, International Finance, 2: 63-83.

Bernanke, B.S., Laubach, T., Mishkin, F.S. and Posen, A.S. (1999) Inflation Targeting: Lessons from the International Experience, Princeton University Press.

Blinder, A. (1998) Central Banking in theory and practice, MIT Press.

Bogdanski, J., Tombini, A., Werlang, S. (2000) Implementing inflation targeting in Brazil, Working Paper Series 1, Central Bank of Brazil.

Brainard, W. (1967) Uncertainty and the effectiveness of policy, American Economic Review, Vol.57, 411-425.

Chadha, J.S. and Schellekens, P. (1999) Monetary Policy Loss Functions: Two Cheers for the Quadratic, DAE Working Papers, Department of Applied Economics, University of Cambridge.

Chow, G. (1975) Analysis and Control of Dynamic Economic Systems, John Wiley and Sons, New York.

Drew and Hunt (2000) Efficient simple policy rules and the implications of potential output uncertainty, Journal of Economics and Business, 52: 143-160.

Estrella, A. and Mishkin, F. (1998) Rethinking the role of the NAIRU in monetary policy: Implications of model formulation and uncertainty, Federal Reserve Bank of New York Research Paper 9806.

Hall, S., Salmon, C., Yates, T. and Batini, N. (1999) Uncertainty and simple monetary policy rules: An illustration for the United Kingdom; Working Paper Series no. 56, Bank of England.

Levin, A., Wieland, V. and Williams, J.C. (1999) Robustness of simple monetary policy rules under model uncertainty, in John B. Taylor, ed., Monetary Policy Rules, Chicago Press.

Levin, A., Wieland, V. and Williams, J.C. (1999) The performance of forecast-based monetary policy rules under model uncertainty, Mimeo, Board of Governors of the Federal Reserve System.

Martin, B. and Salmon, C. (1999) Should uncertain monetary policy-makers do less? Bank of England Working Paper.

McCallum, B. (1999) Recent developments in the analysis of monetary policy rules, Federal Reserve Bank of St. Louis Review, 81(6).

McCallum, B. (2000) The present and future of monetary policy rules, NBER Working Paper 7916.

Orphanides, A. (1998) Monetary policy evaluation with noisy information, FEDS Working Paper 1998-50.

Peersman, G. and Smets, F. (1998) Uncertainty and the Taylor rule in a simple model of the euro-area economy, Working Paper. 
Rudebusch, G. (1998) Is the Fed too timid? Monetary policy in an uncertain world, Federal Reserve Bank of San Francisco Working Paper, forthcoming in the Review of Economics and Statistics.

Rudebusch, G. and Svensson, L. (1998) Policy rules for inflation targeting; Seminar Paper No. 637, Institute for International Economic Studies, Stockholm University.

Sack, B. (1998) Does the FED act gradually? A VAR analysis, FEDS Working Paper 1998-17.

Sargent, T. (1999) Discussion of "Policy rules for open economies" by Laurence Ball, in J.B. Taylor, ed., Monetary Policy Rules, Chicago Press.

Shuetrim, G. and Thompson, C. (1999) The implications of uncertainty for monetary policy, Reserve Bank of Australia, Research Discussion Paper 1999-10.

Simon, H. (1956) Dynamic Programming under uncertainty with a quadratic criterion function, Econometrica, XXIV, 74-81.

Smets (1998) Output gap uncertainty: Does it matter for the Taylor rule?, Mimeo, European Central Bank.

Svensson, L. (1996) Inflation forecast targeting: Implementing and monitoring inflation targets; Working Paper Series no. 56, Bank of England.

Svensson, L. (1997) Inflation targeting: some extensions; Seminar Paper No. 625, Institute for International Economic Studies, Stockholm University.

Svensson, L. and Woodford, C. (2000) Indicator variables for optimal policy, NBER Working Paper 7953.

Swanson, E. (2000) On signal extraction and non-certainty equivalence in optimal monetary policy rules, Working Paper, Federal Reserve Board.

Taylor, J.B. (1993) Discretion versus policy rules in practice, Camegie-Rochester Conference Series on Public Policy 39, 195-214.

Tetlow, R.J. and von zur Muehlen, P. (1999) Can model structure uncertainty imply policy attenuation?, Mimeo, Federal Reserve Board.

Theil, H. (1957) A note on certainty-equivalence in dynamic planning, Econometrica, XXV, 346-349.

Walsh, C.E. (1998) Monetary Theory and Policy, MIT Press.

Woodford, M. (1999) Commentary: How should monetary policy be conducted in an era of price stability?, Federal Reserve Bank of Kansas City. 


\section{Appendix 1 \\ Data description and graphs}

\begin{tabular}{|c|c|c|}
\hline Variable & Name & Source/Definition \\
\hline$\pi$ & Inflation & Monthly percent change in the broad consumer price index (IPCA) from IBGE \\
\hline $\mathbf{r}$ & $\begin{array}{l}\text { Nominal } \\
\text { interest rate }\end{array}$ & Monthly average SELIC overnight interest rate from Brazil's Central Bank \\
\hline d & $\begin{array}{l}\text { Nominal } \\
\text { exchange rate } \\
\text { depreciation }\end{array}$ & Percent change in the monthly average rate from Brazil's Central Bank \\
\hline y & GDP & $\begin{array}{l}\text { Seasonally adjusted monthly chained index series at } 1990 \text { Reais; raw data are from } \\
\text { IBGE }\end{array}$ \\
\hline$y^{*}$ & $\begin{array}{l}\text { Potential } \\
\text { GDP }\end{array}$ & Calculated from equations (6) or (7) in the text \\
\hline u & Output gap & Calculated from equation (5) in the text \\
\hline $\mathrm{i}$ & Investment & Seasonally adjusted monthly index series from IPEA at 1990 Reais \\
\hline c & Consumption & $\begin{array}{l}\text { Seasonally adjusted monthly index series at } 1990 \text { Reais calculated by the authors } \\
\text { as follows: first, we calculated nominal monthly GDP based on IBGE's monthly } \\
\text { chained index series and on FGV's general price index (IGP-DI), using a factor to } \\
\text { make the series consistent with the annual National Accounts figures; second, we } \\
\text { calculated nominal investment based on IPEA's monthly index series and on price } \\
\text { indices for construction (INCC from IBGE) and for machinery and equipment } \\
\text { (IPA-máquinas e equipamentos from FGV), also using a correcting factor to make } \\
\text { the series consistent with the National Accounts; third, we calculated net exports } \\
\text { of goods and non-factor services based on Balance of Payments and exchange rate } \\
\text { data from the Central Bank, again making the series consistent with the National } \\
\text { Accounts; fourth, we calculated nominal consumption as a residual from C = Y - I } \\
\text { - (X-M); finally, we calculated real consumption at } 1990 \text { Reais by using the IPCA } \\
\text { as the consumption deflator and making the series consistent with the National } \\
\text { Accounts. }\end{array}$ \\
\hline $\bar{x}$ & Net exports & $\begin{array}{l}\text { Net exports of goods and non-factor services, calculated as a residual from } x=y- \\
c-i\end{array}$ \\
\hline
\end{tabular}




\section{Graphs}
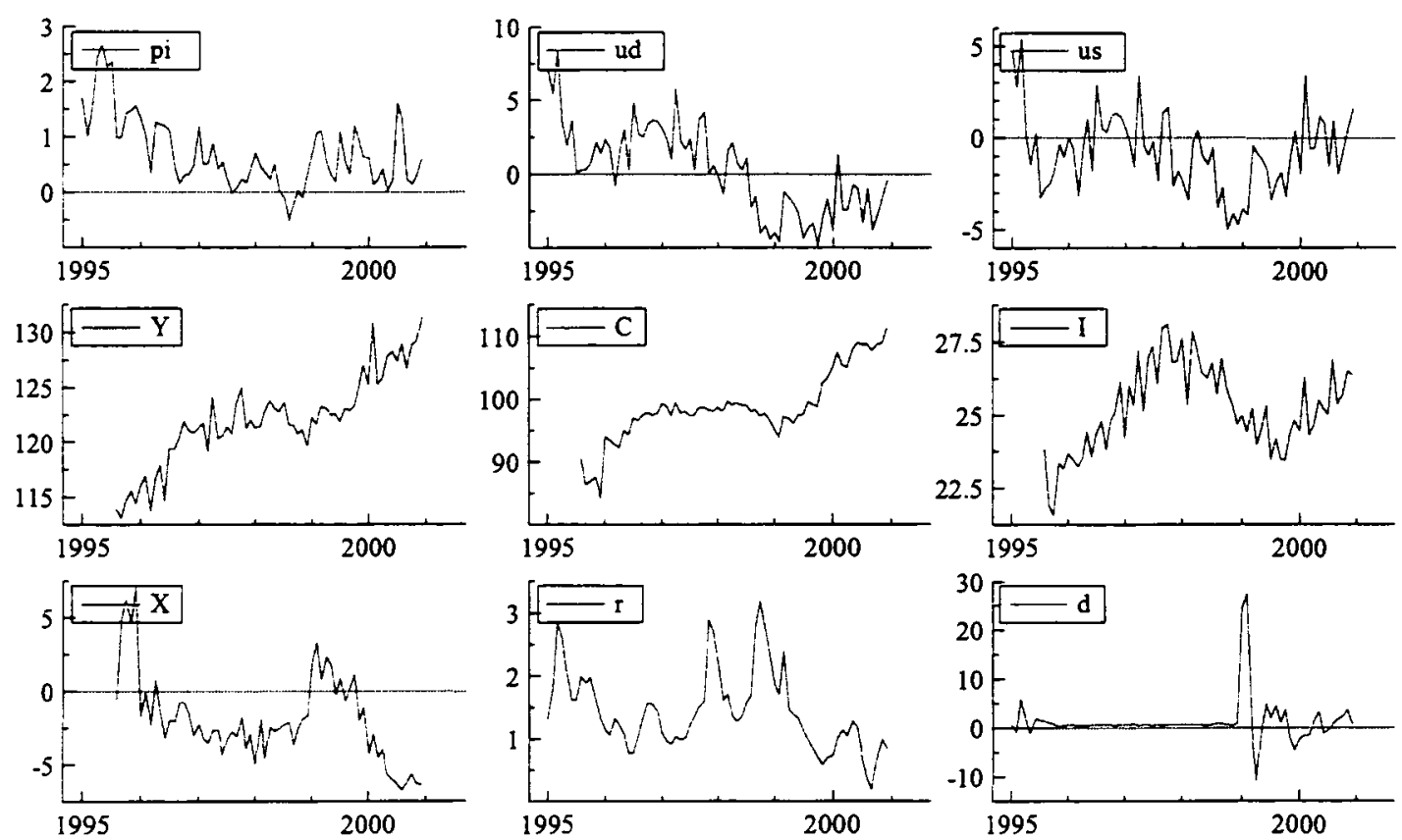

us: $u$ with deterministic potential output ud: $u$ with stochastic potential output 
Appendix 2

Parameter constancy tests for models 1 to 3

Model 1: 1-step ahead (1 up) and break-point (Ndn) Chow tests
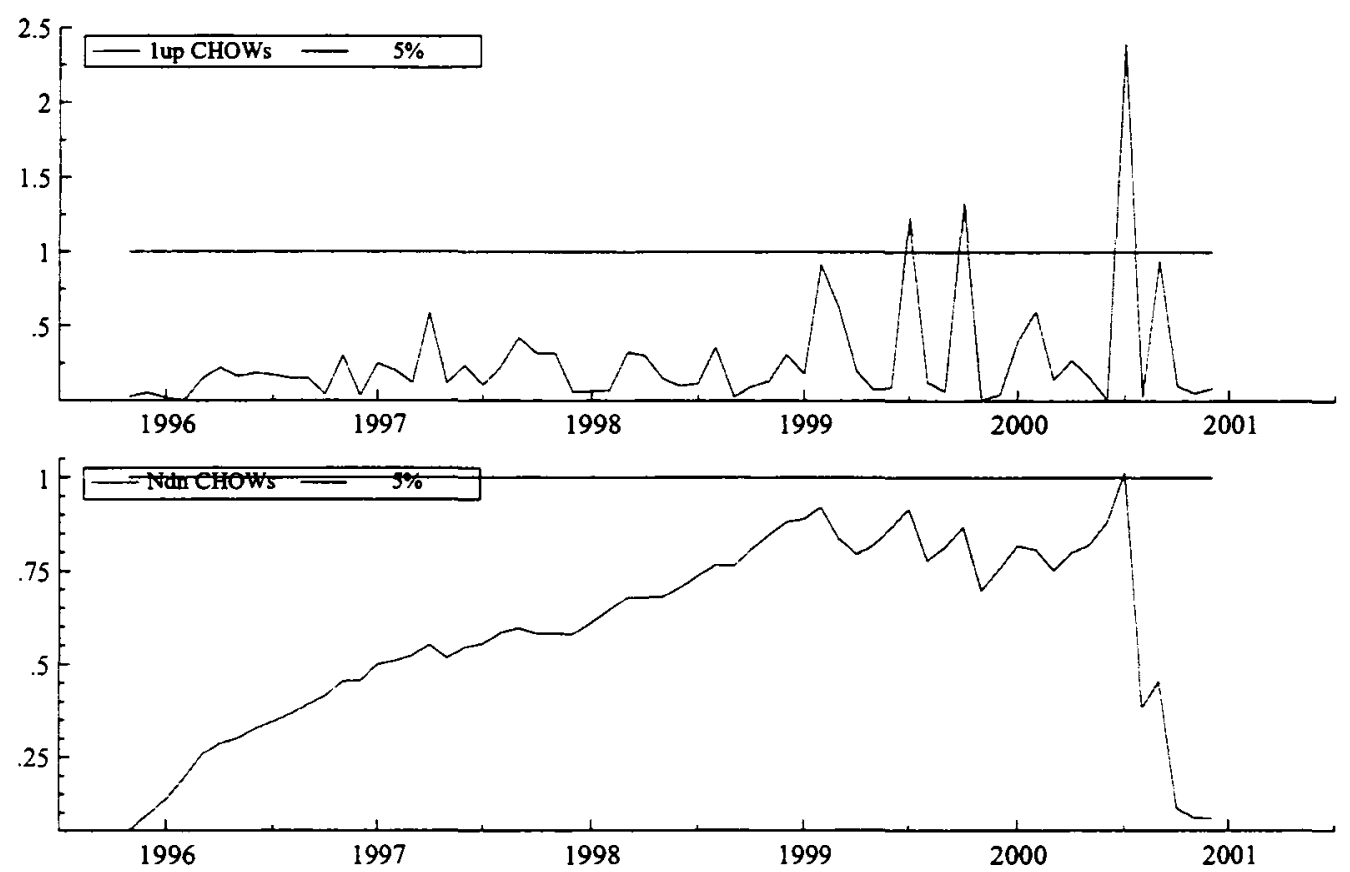

Model 2: 1-step ahead (1up) and break-point (Ndn) Chow tests
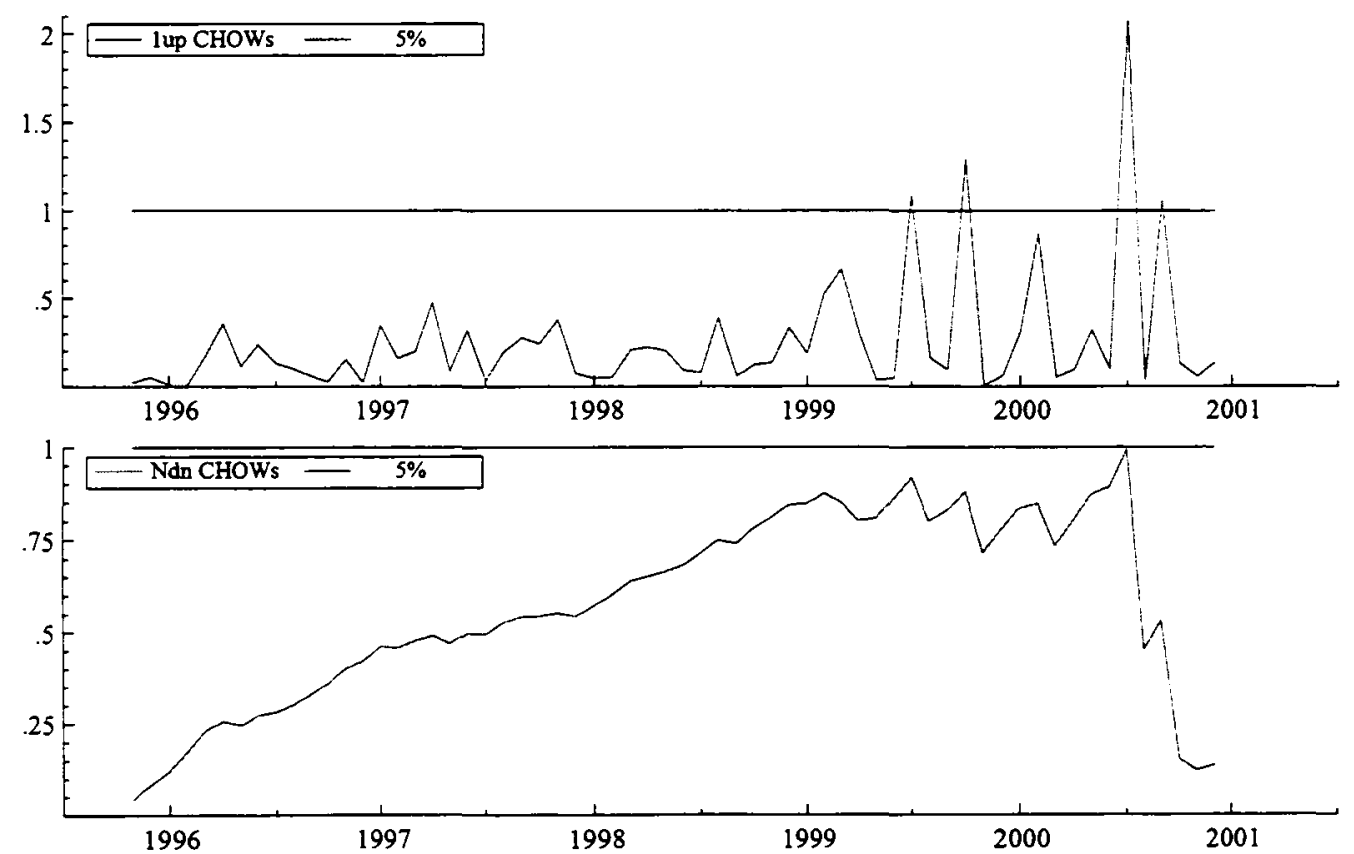

Model 3: 1-step ahead (1up) and break-point (Ndn) Chow tests 

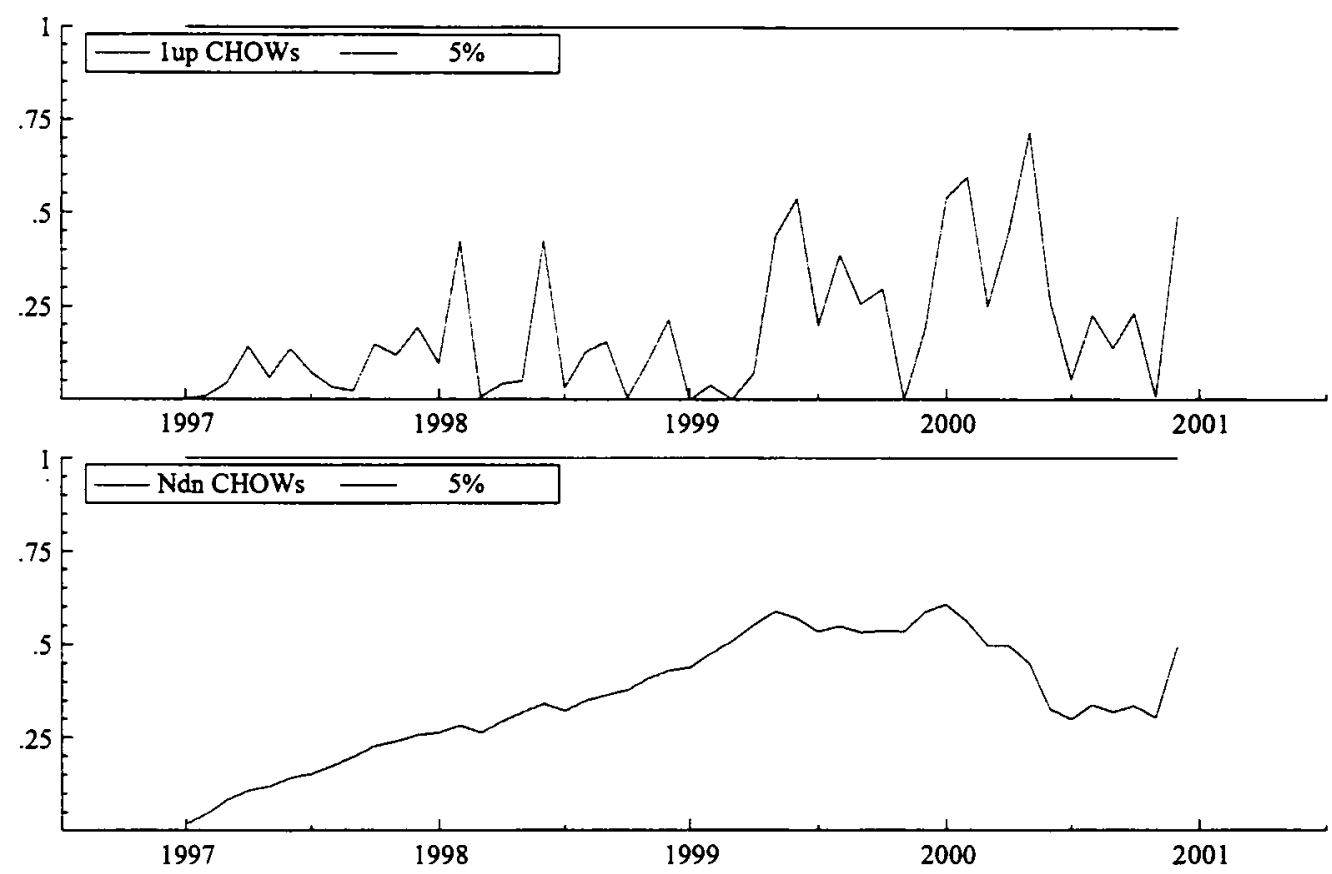


\section{Appendix 3}

Welfare loss for models 1 to 3 under the Taylor rule and under each model's optimal reaction function

Table C.1 - Loss given E(Y) in models 1 to 3 under each model's RF

\begin{tabular}{|l|lrrrrrrr|}
\hline \multicolumn{3}{|c}{} & Mean & \multicolumn{6}{c|}{ Value under risk } \\
\hline $\mathrm{V}(\mathrm{u})+\mathrm{V}(\pi)$ & TR & RF|M1 & RF|M2 & RF|M3 & TR & RF|M1 & RF|M2 & RF|M3 \\
\hline M1 & 0.64 & 0.55 & 0.75 & - & 1.84 & 5.18 & 2.42 & - \\
M2 & 0.97 & 2.46 & 0.93 & - & 2.50 & 2008 & 2.24 & - \\
M3 & 1.36 & 7.61 & 2.51 & 1.07 & 3.64 & 121 & 7.38 & 5.49 \\
\hline
\end{tabular}

Table C.2 - Variance of E(Y) in M1 under M1's and M2's RF

\begin{tabular}{|l|lrrrrr|}
\hline & \multicolumn{3}{|c}{ Mean } & & \multicolumn{3}{c|}{ Value under risk } \\
\hline & TR & RF|M1 & RF|M2 & TR & RF|M1 & RF|M2 \\
\hline$V(u)+V(\pi)$ & 0.64 & 0.55 & 0.75 & 1.84 & 5.18 & 2.42 \\
$V(u)$ & 0.58 & 0.50 & 0.69 & 1.76 & 5.13 & 2.33 \\
$V(\pi)$ & 0.04 & 0.05 & 0.05 & 0.15 & 0.20 & 0.19 \\
$V(d r)$ & 0.12 & 0.22 & 0.03 & 0.35 & 2.76 & 0.10 \\
$V(r)$ & 3.11 & 3.56 & 2.87 & 5.22 & 8.21 & 4.93 \\
\hline
\end{tabular}

Table C.3 - Variance of E(Y) in M2 under M1's and M2's RF

\begin{tabular}{|l|lrrrrr|}
\hline & \multicolumn{3}{|c}{ Mean } & \multicolumn{4}{c|}{ Value under risk } \\
\hline & TR & RF|M1 & RF|M2 & TR & RF|M1 & RF|M2 \\
\hline $\mathrm{V}(\mathrm{u})+\mathrm{V}(\pi)$ & 0.97 & 2.46 & 0.93 & 2.50 & 2008.84 & 2.24 \\
$\mathrm{~V}(\mathrm{U})$ & 0.90 & 2.38 & 0.85 & 2.42 & 2008.08 & 2.15 \\
$\mathrm{~V}(\pi)$ & 0.06 & 0.09 & 0.07 & 0.18 & 3.69 & 0.20 \\
$\mathrm{~V}(\mathrm{dr})$ & 0.41 & 2.02 & 0.11 & 1.13 & 1116.78 & 0.31 \\
$\mathrm{~V}(\mathrm{r})$ & 3.61 & 5.19 & 3.05 & 5.33 & 1409.90 & 4.55 \\
\hline
\end{tabular}

Table C.4 - Variance of $\mathrm{E}(\mathrm{Y})$ in $\mathrm{M3}$ under each model's RF

\begin{tabular}{|c|c|c|c|c|c|c|c|c|}
\hline & \multicolumn{4}{|c|}{ Mean } & \multicolumn{4}{|c|}{ Value under risk } \\
\hline & TR & RF|M1 & RF|M2 & RF|M3 & TR & RF|M1 & RF|M2 & RF|M3 \\
\hline$V(u)+V(\pi)$ & 1.365 & 7.614 & 2.506 & 1.074 & .638 & 121.97 & 7.385 & 5.489 \\
\hline$V(D c)$ & 0.155 & 0.533 & 0.134 & 0.190 & 0.570 & 18.895 & 0.410 & 1.351 \\
\hline$V(D i)$ & 0.253 & 0.553 & 0.243 & 0.313 & 0.649 & 13.667 & 0.575 & 1.079 \\
\hline$V(D x)$ & 0.127 & 0.145 & 0.130 & 0.127 & 0.434 & 0.593 & 0.440 & .480 \\
\hline$V(\pi)$ & 0.031 & 0.083 & 0.048 & 0.03 & 0.134 & 0.390 & 0.193 & 0.156 \\
\hline$V(u)$ & 1.323 & 7.525 & 2.441 & 1.029 & 3.562 & 121.86 & 7.365 & 5.442 \\
\hline$V(r)$ & 3.039 & 5.483 & 2.922 & 3.404 & 5.154 & 49.312 & 4.780 & 6.796 \\
\hline
\end{tabular}


000307807

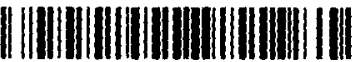




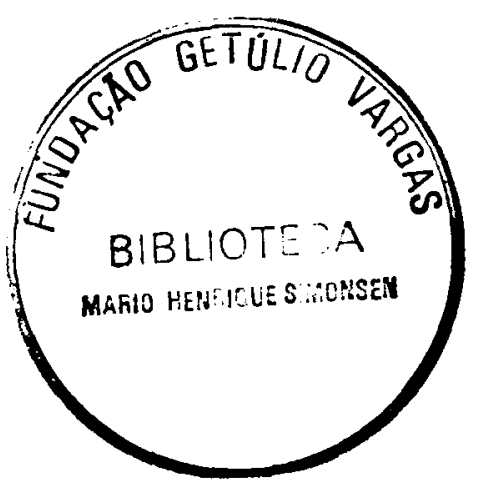

FUNDAÇÃO GETULIO VARGAS

\section{BIBLIOTECA}

ESTE VOLUME DEVE SER DEVOLVIDO Ȧ BIBLIOTECA NA ULTIMA DATA MARCADA

\begin{tabular}{l|l|l|l}
\hline & & & \\
\hline & & & \\
\hline & & & \\
\hline & & & \\
\hline & & & \\
\hline & & & \\
\hline & & & \\
\hline & & & \\
\hline & & & \\
\hline & & & \\
\hline & & & \\
\hline
\end{tabular}

N.Cham. P/EPGE SA M838r

Autor: Moreira, Ajax R. Bello (Ajax Rey

Título: Robustness and stabilization properties of

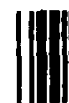

FGV - BMHS
307807

86149

$\mathrm{N}^{\circ}$ Pat: $307807 / 02$

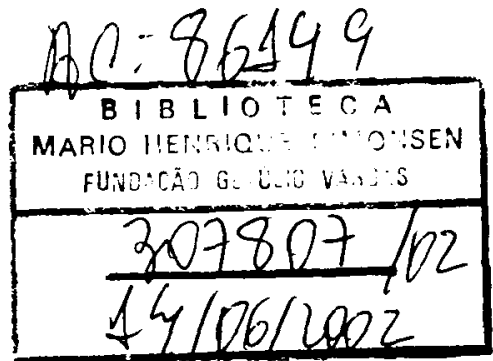

(\&) 